\title{
Powder for Sealant Dosage Form
}

National Cancer Institute

\section{Source}

National Cancer Institute. Powder for Sealant Dosage Form. NCI Thesaurus. Code C149845.

Solid sterile preparation consisting of one or more powder intended to be dissolved in the specified liquid to obtain a sealant. 